\title{
The B Movement in East Africa: A shift in the culture of business
}

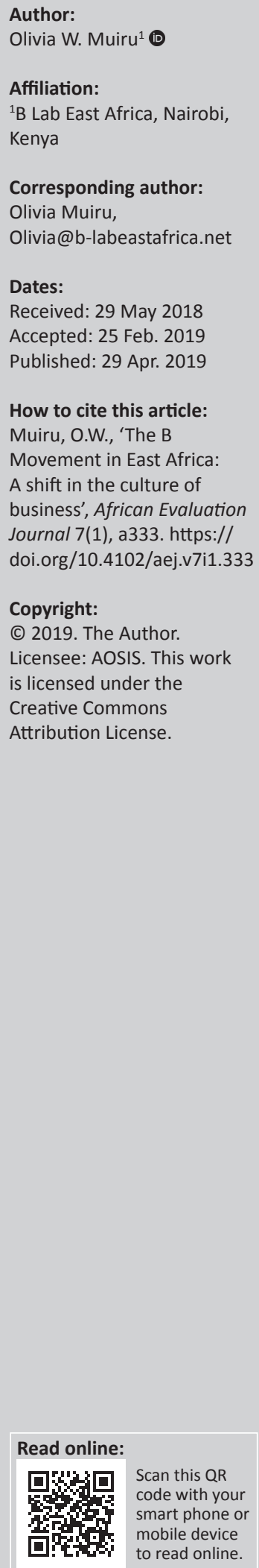

There is a culture shift underway to harness the power of business to help address society's greatest challenges. B Lab East Africa and its network of global partner organisations are uniquely positioned to accelerate this culture shift and ensure it is both meaningful and lasting. We use an integrated approach to systemic change by: (1) building a global community of thousands of credible leaders, Certified B Corporations (B Corps), that meet the highest standards of performance, accountability and transparency, (2) creating pathways that drive millions of businesses to follow these leaders in managing their impact with as much rigour as their profits, and aligning their interests with those of society and (3) inspiring billions to support business as a force for good. B Lab East Africa is engaging with hundreds of African businesses, large and small, as well as investors in assessing, comparing and improving their social and environmental impact. To align their strategies with impact, businesses need to understand where they stand against their perceived impact, how they compare to their peers and how they might improve. To do so, the B Impact Assessment (BIA) offers measurable ways that companies can have a positive impact. It offers step-by-step guidance to assess business practices and tools to make positive changes. By actively measuring their impact, leveraging resource to improve impact and engaging with all stakeholders on impact, we believe this will lead to a more shared and durable prosperity for all.

Keywords: social enterprise East Africa; business with purpose; certification; positive impact; entrepreneurship.

\section{Background}

The mindset of companies was set to the capitalist notion long advocated by Milton Friedman (1962), as originally expressed in his 1962 book Capitalism and Freedom:

There is one and only one social responsibility of business - to use its resources and engage in activities designed to increase its profits so long as it stays within the rules of the game, which is to say, engages in open and free competition without deception or fraud. (p. 133)

According to Friedman, business had no role to play in addressing social and environmental challenges. And true to the fact, capitalism delivered what it promised: it provided unprecedented wealth and prosperity around the world. But it also led to negative effects - wealth inequality ${ }^{1}$ creating limited access to basic services for those who cannot afford, skewed tax systems, environmental degradation, political instability, just to name a few (Pimentel 2018).

However, over the years there has been recognition that business needs to consider how it engages with broader stakeholders, not just shareholders. External factors, including scarce resources and climate change, growing consumer demand for socially responsible brands, workers demanding socially and ethical companies, are pushing companies to introduce holistic changes in the way they operate. Growing external pressures not only reward this approach but also require it (SustainAbility 2015). Some of the theories prompting businesses to look at broader stakeholders include, but are not limited to, the following (Table 1).

The theories or approaches have, over the decades, provided different points of views of how business can work for the betterment of society, and companies are rising to the challenge (Barton, Horváth \& Kipping 2016):

We have reached a tipping point where we cannot continue on the current path. No business can prosper in a world of runaway climate change, or one with rampant inequality and poverty. Business leaders are starting to recognise, perhaps for the first time in large numbers, that the cost of inaction is now greater than the cost of action. Paul Polman, former CEO of Unilever. (pp. 17-32)

1.In Oxfam's 'Reward Work, Not Wealth Report', the organisation highlights new data from Credit Suisse, showing the richest 42 people in 2018 owned the same amount of wealth as the bottom 3.7 billion people in the world. 
TABLE 1: Examples of theories or approaches on responsible business.

\begin{tabular}{ll}
\hline Theory & Description \\
\hline Corporate Social & Seen as philanthropic and opt in, companies with CSR \\
Responsibility (CSR) & $\begin{array}{l}\text { initiatives often undertake different causes to help society or } \\
\text { environment based on activities not core to the company. A } \\
\text { major criticism of this approach is that it does not tie into the } \\
\text { long-term goals of a company and can lead a company to } \\
\text { taking too narrow approach in external engagement, coming } \\
\text { across as public relations initiative that is disingenuous } \\
\text { (Browne \& Nutall 2015). }\end{array}$ \\
$\begin{array}{ll}\text { Triple Bottom Line } \\
\text { (TBL) }\end{array}$ & $\begin{array}{l}\text { In 1990s, John Elkington and others took a different approach. } \\
\text { They proposed that companies need to have a TBL approach in } \\
\text { how they operated and reported on their performance. TBL } \\
\text { approach suggests that companies not only look at profit but } \\
\text { also account for how their activities affect people and planet } \\
\text { (Henriques 2013). The TBL approach is vested in the concept } \\
\text { that only when companies measure and account for all areas } \\
\text { they impact }{ }^{2} \text { they can operate responsibly (Brusseau 2013). }\end{array}$ \\
Stakeholder Theory & $\begin{array}{l}\text { This theory suggests that companies should consider all those } \\
\text { who are impacted by their work. In its purest form, a drawback } \\
\text { to the theory holds that all stakeholders have a right in } \\
\text { participating in the business. This is not practical for a } \\
\text { company to execute to survive by waiting on feedback from } \\
\text { the community on each activity (Brusseau 2013; Phillips 2012). }\end{array}$ \\
&
\end{tabular}

For businesses to make a cultural shift in how they work, there is a need to bring in all stakeholders to create a supporting ecosystem where:

- investors follow a similar investment as impact investors, ${ }^{3}$ where they consider financial, social and environmental returns when making investment decisions

- legal corporate structures are in place that legally bind companies to consider all stakeholders in decisionmaking and bind corporate mission, even if there is a change in ownership

- consumers buy goods and services that are values-aligned (Knowles 2016)

- constructive collaboration happens among business, civic organisations, academic institutions and governments to enable knowledge sharing, and independent checks and balance

- like financial reporting, a set of agreed standards is in place that enables companies to measure, manage, improve and report on their social and environmental performance $^{4}$

- media coverage highlights good companies, not only financial performance and CSR initiatives.

This does not mean that business is the only solution to current social and environmental challenges, rather it is recognising that business can be a significant contributor to creating and scaling solutions. Furthermore, that business has a necessary role to play because government and nonprofits are, like business, necessary and also insufficient to solve our most challenging problems alone.

2.Global Reporting Initiative defines impact as the effect an organisation has on the economy, the environment and/or society, which, in turn, can indicate its contribution (positive or negative) to sustainable development - https://www. globalreporting.org/standards/questions-and-feedback/materiality-and-topicboundary/

3.The Global Impact Investing Network (GIIN) defines impact investments as investments made with the intention to generate positive, measurable social and environmental impact alongside a financial return. Impact investments target a range of returns from below market-to-market rate, depending on investors' strategic goals.

4.The triple bottom line approach requires companies to keep accounts profits and create a value system for impact on people and planet as well. Organisations such as Sustainability Accounting Standards Board and Global Reporting Initiative have provided indicators to support companies.
B Lab, a global non-profit, is working to accelerate the business culture shift towards positive impact and make this shift meaningful and lasting. The organisation does this by creating a supportive ecosystem to support businesses as a force for good.

\section{These include the following:}

- administration of the B Impact Assessment (BIA) tool used by companies and investors to measure and manage impact

- certification of high-impact business as Certified B Corporations (B Corps)

- advocacy for governance structures that promote creation of a solid foundation for long-term mission alignment and value creation through benefit corporation.

For this to be truly global, B Lab works with regional partners based in North and South America, Europe, Australia and Africa. In partnership with the UK's Department for International Development (DFID), B Lab East Africa ${ }^{5}$ was established in 2017 to support this system shift in the region. An overview of how the work that B Lab does globally and in East Africa ties to the global shift in business culture is given below.

\section{The B Impact Assessment platform}

The BIA is a comprehensive measurement and management tool focused on a business's positive impact on society and the environment. By completing a set of questions that reflect impact indicators, best practices and outcomes, ${ }^{6}$ a company receives a score on a 200-point scale: such score is representative of the business's overall impact on its employees, communities and the environment.

Although questions are designed to be universally applicable for the purposes of standardisation, they are also designed to allow for local context in how a company completes the assessment. The BIA is customised to a company based on size (number of employees), sector and geographic market (region where the company has the majority of its operations) ${ }^{7}$ (Figure 1).

The BIA is defined as follows:

- Positive impact oriented: All indicators represent the positive impact of a company and are intended to exceed universal business norms. There are no negative points in the assessment. ${ }^{8}$

- Comprehensive: The assessment takes a holistic view of business impact by including indicators and best practices

5. B Lab East Africa covers Kenya, Uganda, Rwanda, Burundi, Ethiopia, South Sudan and Sudan.

6.Outcome, as it relates to business, is viewed as a change that is caused by an action or activity. This change can be for an individual or a group of individuals (who could constitute an organisation), but it must be as a result of an activity conducted by the business - www.socialvalueselfassessmenttool.org

7.There are currently over 70 version of the $\mathrm{BIA}$, determined by the tracks.

8.Because there are no negative points in the assessment, the weighted questions do not include questions about negative impacts or legal compliance. A separate unweighted disclosure questionnaire is included in the BIA to examine a business's negative attributes and negative outcomes. 


\section{B Impact Assessment: Track determinant}

Size: Working Owners, 1-9, 10-49, 50-250, 250-1000, 1000-10000, 10000+

Market (geography): Developed Markets (DM) and Emerging Markets (EM)

Sector (industry): Manufacturing, Service, Wholesale/Retail, Agriculture

\section{Company Details}

Tell us a little bit about your company so that we can tailor your assessment. Company Name

In which country are a majority of your company's workers or facilities located?

Country

Select Country

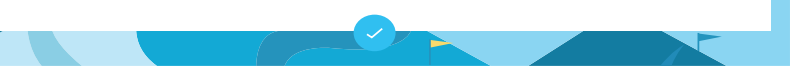

Company Sector \& Industry

EXPLAIN THIS

Select the sector and industry that best describes your business.

It is okay if the description does not perfectly fit. If your business operates in multiple industries, please
select the industry that represets the largest operating activity of the business in terms of overall revent

Wholesale/Retail

Industry

Bevorages

FIGURE 1: B Impact Assessment track determinants.

affecting all stakeholders and encompassing all aspects of a business's operations and business model.

- Objective: All weighted questions in the assessment are specific and verifiable - questions are intended to be supported by documentable evidence for each indicator to maintain the rigour and value of the assessment. The BIA also relies on relevant third-party certifications (Fair Trade, USDA Organic, Cradle-to-Cradle, LEED, etc.) (see Appendix 4) to leverage third-party expertise and verification, and is intended to complement rather than substitute other certification and impact measurement frameworks. ${ }^{9}$

- Standardised: To provide a comparable measure across all types of businesses, the assessment has identical structures for all businesses, with the same stakeholders and dimensions of impact influencing those stakeholders (referred to as 'goals').

\section{B Impact score and structure}

All versions of the BIA are divided into three distinct sections:

- Operational Impact: It evaluates the operational impact of the company on its stakeholders, as it is managed and operated on a day-to-day basis. All company activities have an impact on stakeholders, and this section offers a holistic measure of operational impact.

- Impact Business Model: It evaluates the specific business models designed to create positive social and/or environmental impact beyond the basic operational impact of the business. Impact business models are marked by more intensive, generally intentional, systems of measurement and management.

9.Appendix 4 offers an overview of the BIA and how it relates to other impact measurement tools.

\section{What does the B Impact Assessment Measure?}

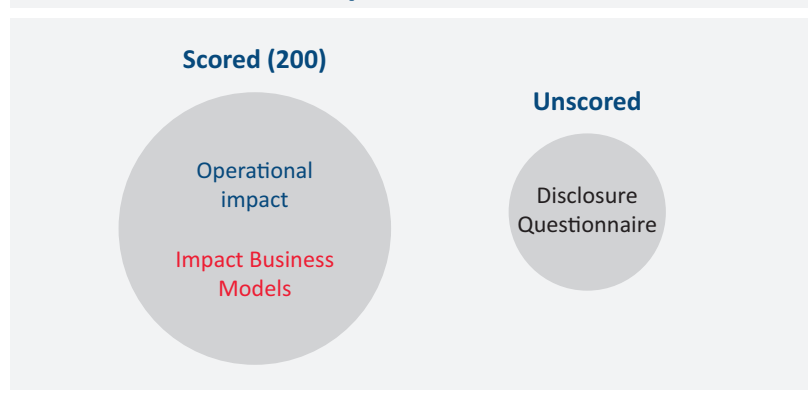

FIGURE 2: B Impact Assessment (BIA) scored and unscored sections.

- Disclosure Questionnaire: It is an unscored section of the assessment that includes questions about negative practices or outcomes or legal compliance of a business operation.

The first two sections make up the scored portion of the impact assessment. A company can score up to 200 points in these two sections (Figure 2). ${ }^{10}$

Within these two scored sections, there are four distinct impact areas:

- Governance:The extent to which social and environmental considerations are ingrained into the business, financial responsibility and oversight, transparency, and the prevention of negative outcomes.

- Workers: The company's contribution to the financial, social, physical and professional well-being of its employees.

- Community: The company's contribution to the economic and social well-being of the communities in the area in

10.To learn more about how the scores are determined and allocated in the assessment, visit https://bimpactassessment.net/how-it-works/frequently-askedquestions/the-b-impact-score. 
which it operates, including job creation and inclusivity, civic engagement and philanthropy, and collaboration with other businesses and organisations.

- Environment: The company's efforts to reduce its environmental footprint, as created by company facilities, input materials, outputs or wastes and suppliers or distributors.

\section{Governance of the B Impact Assessment}

The BIA is developed and managed by B Lab with oversight from an independent Standards Advisory Council (SAC) composed of stakeholder representatives and impact experts. In addition to the SAC, B Lab has Regional Advisory Groups whose mandate is to deepen the engagement of regional experts in improving the standards of the BIA. Currently, B Lab has advisory groups in Latin America, East Africa, Australia and the United Kingdom that provide constructive feedback and recommendations on regionalspecific issues. ${ }^{11}$

\section{Uses of the B Impact Assessment}

The BIA platform is a free public good, available for anyone at bimpactassessment.net. Originally developed in 2007, there have been more than 60000 businesses to date that have registered to use the BIA.

The BIA can be used for the following purposes:

- Assess and compare performance: By completing the assessment, a company receives an overall score to understand its overall impact. Benchmarks within the assessment are available to understand how the company compares to other similar businesses.

- Improve practices: The assessment is designed to be educational and give companies direction on how to improve their overall impact. Companies are able to mark questions for improvement, scores can be tracked over time and questions feature resources - best practices, examples from other companies on how they implement different practices - to support companies in their improvement journey:

The BIA broadened what we considered as impact. There are very many areas Peperuka had never considered in terms of impact [sic] e.g. we had never thought about things like the lights we use in the office. We are now working on an improvement plan as well as documentation and tracking of our procedures so as to show our impact. We are now talking to our networks about the BIA and how other businesses can use the assessment to improve on their current operating procedures. Wangari, Founder of Peperuka. ${ }^{12}$

- Become B Corps Certified or get a Global Impact Investing Rating System (GIIRS): The BIA is the exclusive assessment tool used to earn B Corp certification or receive a GIIRS rating

11.The BIA is revised and upgraded on a 3 -year cycle with an effort to continually improve how it measures impact. Improvements are made based on feedback from assessment users, B Lab staff and third-party experts.

12.https://b-labeastafrica.net/case-study-peperuka/
- Evaluation of the performance of other businesses that an institution partners with, like investees or suppliers.

Since B Lab East Africa started operating in East Africa, over 600 companies have registered on to the BIA platform. A further 200 companies have registered on to the platform in the rest of Africa. Majority of the companies in East Africa are using the assessment for impact measurement and management. The use of inbuilt improvement tools and benchmarking helps companies to track how they perform as it relates to social and environmental performance. This is available as a free public good.

B Lab and its regional partners offer paid services to support organisation to verify BIA performance. Users of these services generally fall into one or more of the following categories:

- B Corps: The BIA is the exclusive assessment used to verify the performance requirement to become B Corps.

- GIIRS-rated funds and companies: The BIA is used to issue GIIRS ratings - equivalent to a Morningstar rating ${ }^{13}$ for impact rather than financial viability.

- Community partners: The BIA is used by business associations, municipalities, large companies and nonprofits to advance the positive impact of their constituent businesses.

\section{Certified B corporation}

B Corp is to business what Fair Trade certification is to coffee or USDA Organic certification is to milk. B Corps are for-profit companies certified by B Lab to meet rigorous standards of social and environmental performance, accountability and transparency. The global B Corp movement is an example of the shift in business culture, to use business as a force for good.

\section{Certified B Corps:}

- achieve a minimum verified score of 80 points on the BIA; assessment answers are verified by B Lab

- make their B Impact Report transparent on bcorporation.net

- amend their legal governing documents to require their board of directors to balance profit and purpose (see Appendix 2) $)^{14}$

- update their certification every 3 years (Box 1 ).

\section{B Corp movement in East Africa}

There are over 2700 B Corps from more than 60 countries globally. They vary in size from billion-dollar companies, like Danone North America and Laureate Universities, to

13.The Morningstar star rating is a rating given to mutual funds (and other managed products) by the investment research firm Morningstar. The ratings range from one to five stars, with one being the poorest and five being the best. The ratings are a snap shot of risk-adjusted performance at a point in time'. https://www. thriventfunds.com/mutual-funds/morningstar-ratings.html.

14.B Corps make this legal change by updating their articles of incorporation reincorporating as benefit companies or making other structural changes. The $B$ Corp Corp legal framework helps companies protect their mission through capital raises and leadership changes and gives entrepreneurs and directors more flexibility when evaluating potential sale and liquidity options (see Appendix 2 on article amendments required of Kenyan B Corps). 
BOX 1: B Corp certification process. 1. Take the B Impact Assessment (BIA): The first step in becoming a Certified B
Corporation is taking the BIA, which assesses the overall impact of your company
on its stakeholders. The assessment varies depending on the company's size
(number of employees), sector and location of primary operation.
2. Submit supporting documentation: Following completion of the BIA, supporting
documentation is asked to be uploaded. The assessment will randomly select six
to eight questions that were answered in the affirmative regarding the
operations of the company to demonstrate those practices in more detail.
3. Assessment review call: A B Lab staff member will have a call with the company
to review questions and documents provided by the company.
4. Submit additional documentation: Post the review call, companies that meet a
score above 80 out of the 200 points will typically be asked to provide additional
documents specifically from the Impact Business Model section of the
assessment that were answered in the affirmative.
5. Background checks: In addition to the voluntary indication of sensitive issues in
the Disclosure Questionnaire, companies pursuing certification also are subject
to background checks by B Lab staff. Background checks include a review of
public records, news sources and search engines for company names, brands,
executives or founders and other relevant topics.
6. Completion of certification: If the score of the BIA after the review process is
above 80 points, the company will be asked to sign the B Corp Term Sheet
(Appendix 3 ) and this will mark the end of the certification process.
*Site review: $10 \%$ of B Corps are randomly selected each year for an in-depth
site review. The goal for this review is to verify the requirements of the
certification and further confirm the accuracy of affirmative responses in the
company's BIA.
* Recertification: To maintain B Corp certification, a company must update their
assessment every 3 years. This process ensures that companies who become B
Corps continue to engage in a high level of impact with their stakeholders, even
as the business grows or changes.

Source: Adapted from B Corp. n.d., B Corporation, viewed n.d., from https://bcorporation. net/certification

Note: Read more about the certification process and cost at https://bcorporation.net/ certification.

start-up organisations. B Corps include various industries and can be publicly traded or private companies.

In East Africa, there are currently 27 B Corps. ${ }^{15}$ These include high-impact social enterprises that target Bottom of the Pyramid (BoP) like Daproim Africa and Eco2Librium, sustainable consulting firms like Greyfos Consulting and Sustainable Business Consulting, and manufacturing company Oliberté. These are companies that pursued certification for a myriad of reasons:

- Join a community: B Corps are able to connect with their peers to learn from and do business with, given their shared value that is reflected through the certification. For example, Sistema Bioblosa (a B Corp with operations in Kenya) was able to fundraise using Lendahand Crowdfunding, a B Corp in the Netherlands. ${ }^{16}$

- Benchmark and improve performance: B Corps use the BIA to take a 360-degree look at company practices and identify ways to improve over time. B Corps also connect with, collaborate with and learn from their highperforming peers, continually challenging themselves to improve. ${ }^{17}$

- Build credibility and amplify voice: By verifying a company's performance using third-party standards, B Corp certification differentiates companies with good practices from those that just have good marketing.

15.The B Corps are based in Kenya, Uganda, Ethiopia, Rwanda and Tanzania.

16.https://www.lendahand.com/en-EU/projects/5880-sistema-bio.

17.An example of collective effort for improvement is the ongoing $B$ Inclusive Economy challenge. Each year, B Corps can opt in to the challenge and identify areas for improvement as it relates to inclusive practices in their community, workforce, the environment and supply chain. https://bcorporation.net/for-b-corps/inclusiveeconomy-challenge.
BOX 2: Engaging employees: Tal Dehtiar, Founder of Oliberté Shoes (Certified B

Corp).

'Being a B Corp allows us to show that it's possible to play in the mainstream while making change, and to brush shoulders with and be motivated by other such inspiring companies'. ${ }^{18}$

What matters most to your company?

Being the role model for fairly manufactured goods in sub-Saharan Africa.

What did you learn by taking the Assessment?

When we started, our employees in Ethiopia neither understood nor recognised that what we were doing was creating impact. But taking the assessment was a validating exercise for our employees - it showed the team that we were already doing some amazing stuff with our company. It also showed us where we needed to improve to become the role model we want to be.

What did you do as a result of taking the assessment?

Since then, we have taken the steps to certify our factory as the first Fair Trade footwear factory in Africa. We also found that the biggest gaps in our results were in the Environment section. We are continuing to educate our leather and rubber suppliers on how they can reduce their footprints. We have also made a commitment to donate $1 \%$ of our profits to environmental causes through $1 \%$ for the planet.

Source: Wilson, F., 2016a, Case studies, viewed January 2019, from B-Aalytics: http://b-analytics. net/customers/case-studies/using-b-impact-assessment-engage-employees

- Attract talent and deepen engagement: Certifying as a B Corp helps companies in attracting values-aligned talent and keep them engaged over time (Giddens 2018). B Corp Oliberté uses the BIA process to engage their team on impact the company is creating (see Box 2).

The B Corp certification is still relatively new in East Africa, with the B Corp community a little over a year in market with a significant concentration in Kenya. The expectation is that with time companies will be able to attract new customers, employees and investors through their certification. Data from other markets in the world, where B Corps have been around for more than 2 years, are encouraging. The UK B Corp community in 2018 showed that B Corps in their market had grown at an average rate of $14 \%$ per annum (Giddens 2018). Danone, parent company of the largest B Corp Danone North America, was able to leverage B Corp certification to access finance. In 2018, 12 of the largest banks in the world syndicated a 2 billion euro bank loan to Danone with interest rates that reduced:

as Danone progresses on its B Corp (and other ESG) metrics. The paradigm shift is in fact that these banks have identified B Corp as lowering the beta risk of our credit status. (Faber 2018)

Outside of East Africa, there are grassroots communities of B Corps coming up in South Africa (eight B Corps), Zambia (one B Corp), Mozambique (one B Corp) and Ghana (two B Corps).

\section{Global Impact Investing Rating System rating}

A new subset of investors, Impact Investors, has risen intentionally seeking investments in companies that not only have good practices but also have measurable positive social impact (United Nations Development Programme [UNDP] 2016). These investors tend to seek deeper and direct social impact and approximately $\$ 60$ billion are already under management using impact investment strategies (Kassoy, Houlahan \& Gilbert 2016).

B Lab works to support these investors to measure, report and improve on the impact of their investments through the GIIRS. 18.why we became a B Corp - Oliberte - https://www.bcorporation. net/community/ oliberte-limited. 
BOX 3: Using B Impact Assessment as an investor: Brian Cayce, VP of Social Venture Group, Gray Ghost Ventures.

How did your portfolio companies manage the GIIRS process?
We always have a motivation to shield our entrepreneurs from too many requests
because founders are often pulled in multiple directions and wear many hats. We
surveyed our companies after they completed the GIIRS ratings process. Over $80 \%$
of companies did not find the process burdensome and some of the companies
were thrilled with the nature of the questioning.
What did companies find valuable?
Many CEOs saw a corroboration between our investment expectations and a
third-party requirement, especially in areas of governance and reporting. For
example, all the companies began to understand better why we emphasise
stakeholder language in companies' constitutional documents. They learned that
this requirement was not idiosyncratic to Gray Ghost and that incorporating this
language into bylaws can lead to a bigger movement for a larger swath of the
social impact population. The scorecard framework of the impact report helped
companies identify strengths and weaknesses and set impact objectives. Our
companies tended to score very highly on the impact business models and
community areas because that is their focus through their product or service. On
the contrary, because of the early stage nature of our companies, the assessment
illuminated some topics that will be important in the future enabling the
companies to put policies in place in advance.
Did any companies make changes to their operations or practices after taking
the assessment?
Many HR departments made efforts to shift around their employment practices,
especially in training and onboarding new hires. Equity incentive pools have
expanded for the companies that are building for growth and liquidity. Many of
our companies operate in geographies where the notion of an independent board
is not widespread, but the assessment helped highlight to them how this
governance structure could make the company stronger. They also began tapping
other resources via a network of advisory board members or less formal bodies.

Source: Wilson, F., 2016b, Case studies, viewed May 2018, from B-Analytics: http://b-analytics. net/customers/case-studies

GIIRS ratings support funds that manage their portfolio's impact with the same rigour as their financial performance. Using the BIA as the measurement tool, GIIRS delivers a comprehensive accounting of a portfolio's impact on all stakeholders. Funds can use the rating to prove impact thesis, track progress over time, amplify impact through improvement tools, and benchmark and report their portfolio performance (see Box 3 on how Gray Ghost Ventures uses GIIRS rating).

To complete a GIIRS rating for a fund, the fund's portfolio companies must complete the BIA and the fund completes a fund manager assessment. A GIIRS fund rating is composed of an aggregate numerical score and rating for a fund based on a roll-up of score of the BIA for its portfolio investments.

Each year a fund receives an updated rating with current information about the investments in its portfolio. At the close of a fund, funds receive a track record rating - a report summarising its impact performance over the life of the fund (Figure 3).

\section{Community partners}

Major institutions are helping the companies in their network measure and manage their positive impact through BIA. In partnership with B Lab, these partners (including non-profits, associations and large corporations) use the BIA as a tool to help advance the positive impact of their constituent businesses, suppliers or subsidiaries.

By using the assessment, these institutions deliver a comprehensive accounting of the impact of their supply chain or network members or subsidiaries on workers, customers, communities and the environment (see Box 4). ${ }^{19}$

19.You can learn more about these programmes on http://b-analytics.net/.

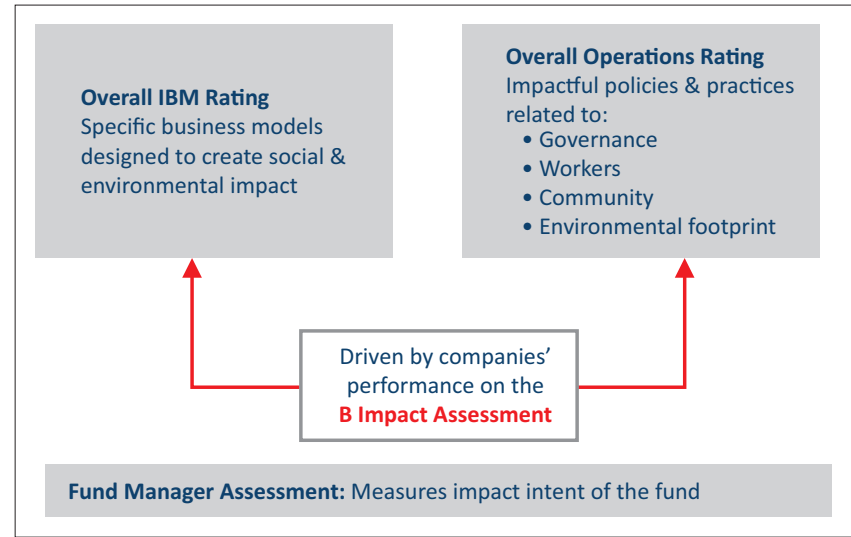

Note: Learn more about Global Impact Investing Rating System rating, http://b-analytics. net/giirs-funds.

FIGURE 3: Global Impact Investing Rating System (GIIRS) Fund Rating Structure.

BOX 4: Case study: Supply chain management: Bancolombia Sustainability Project: Andres Felipe Perilla Rodriguez, Sustainability Director.

In 2016, Grupo Bancolombia, the largest bank in Colombia, in collaboration with B $\mathrm{Lab}$ and its sister organisation in Latin America, launched a programme to use the B Impact Assessment to measure and manage the social and environmental impacts of 100 of its key suppliers, to enhance the positive impact of the bank and its value chain.

Why was B Lab's programme the right choice for Bancolombia?

Bancolombia had several programmatic objectives: (1) to understand how the companies in its supply chain are mission-oriented businesses; (2) to improve the sustainability performance of its supply chain and (3) to strengthen the bank's relationship with its suppliers. To fulfil these objectives, it was essential that the programme included the following:

- a self-assessment tool that went beyond ESG evaluation, to allow suppliers to understand their social, environmental, governance and economic impacts of their businesses on society

- an analytics platform that provided both a holistic view of the impact of the bank and its network in their local community and that allowed the bank to focus on impact improvement with the businesses in its supply chain

- after evaluating numerous impact assessment tools used by banks and corporations, Bancolombia chose the tools - the B Impact Assessment and corporations, Bancolombia chose the tools - the B Imp
B-Analytics - as the best solution to fulfil its objectives.

How did Bancolombia's pilot programme work?

At a launch event that convened Bancolombia's largest suppliers, 100 missionoriented suppliers were asked to complete the B Impact Assessment. In addition oriented suppliers were asked to complete the B Impact Assessment. In addition identify two to three actionable areas for improvement over the next 12 months. identify two to three actionable areas for improvement over the next 12 months. Bancolombia ultimately invited 145 suppliers, of which over 111 completed the B
Impact Assessment.Once the suppliers had completed the B Impact Assessment, Impact Assessment.Once the suppliers had completed the B Impact Assessment, sustainability team used the data in its ESG supply chain analysis and reporting ${ }^{20}$ and generated performance reports for suppliers who completed the B Impact Assessment, highlighting areas for improvement, which allows Bancolombia to better understand the scale and composition of its supply chain.

What were the outcomes of the programme?

More than $80 \%$ of suppliers completed the entire B Impact Assessment. In aggregate, those suppliers directly or indirectly employ more than 600000 workers, allowing Bancolombia to better understand the scale and composition of its supply chain. Some statistics from the program include the following:

- suppliers created over 17656 jobs last year

- on average, women hold $36 \%$ of executive positions at Bancolombia's suppliers - $34 \%$ of suppliers have a high-to-low-pay ratio between 1 and $5 x$, while $14 \%$ have a high-to low-pay ratio greater than 20 times

- $68 \%$ of suppliers have an environmental policy, while $16 \%$ monitor their energy consumption, and $11 \%$ of suppliers have a certified environmental management system.

Source: Wilson, F., 2016b, Case studies, viewed May 2018, from B-Analytics: http://b-analytics. net/customers/case-studies

\section{Beyond measurement, impact governance}

The growth of the B Corp movement and use of the BIA has led to growing interest in corporate structures that enable business to embed purpose in their legal documents of incorporation. B Lab works to promote the creation of a solid foundation for long-term mission alignment and value

20 The 2016 report, including results from the programme, can be found on the following website: https://www.grupobancolombia.com/wps/wcm/connect/1b350d27 8c7a-4840-b6b3-08d31e6c1e46/Informe+Gestion+2016.pdf?MOD=AJPERES \&CVID $=\mid \mathrm{HnnX}$ XS 
creation through benefit corporation. Benefit corporation is a corporate structure that aligns the interests of business with those of society and helps high-impact businesses to be built to last. The benefit corporation structure protects mission through capital raises and leadership changes, creates more flexibility when evaluating potential sale and liquidity options, and prepares businesses to lead a mission-driven life post-IPO (Kassoy et al. 2016).

Benefit Corporations have an expanded purpose beyond maximising share value to explicitly include general and specific public benefit. They are required to consider or balance the impact of their decisions not only on shareholders but also on their stakeholders. B Lab collaborates with the capital markets and policymakers to drive adoption (you can view the work on http://benefitcorp.net/). Benefit Corp legal structure is currently recognised in more than 30 states in the United States and Italy. ${ }^{21}$ In East Africa, there are two companies that have registered in the United States as a Benefit Corp to act as a clear signal to investors, consumers, workers and suppliers of their commitment to both generate profit and positive impact. B Lab East Africa is in the process, with support from legal law firms, of researching the different corporate legal structures in the market and how Benefit Corp legislation can be applied.

\section{Conclusion}

There is proof that businesses cannot continue to operate as they currently do; it is not sustainable for long-term development and profitability. Business can play an important role in addressing society's greatest challenges, together with government and civil society. For business to be an agent of change, credible standards and public transparency are necessary for customers, investors, policymakers and workers to differentiate good companies from just good marketing.

Credible standards hold businesses accountable and transparent about their impact performance. The BIA, Fair Trade, Sustainable Development Goals and Organic Certification are some of the standards enabling businesses to measure the impact their activities are creating on workers, suppliers, shareholders, the environment and the community they serve.

Measuring impact also enables companies to look holistically at their performance and work on improvement where needed. This works similar to how companies use financial reports to set goals for revenue, profit and expenses for the year. Tracking desired systemic outcomes (e.g. poverty was reduced because of a company product or service) will take years. By building impact metrics directly into company's systems, companies will be able to track progress towards both near-term and long-term impact goals.

For business culture to shift, the capital markets infrastructure is critical to channelling capital to high-impact enterprises.

21.Learn more on B Corp at http:///benefitcorp.net/.
The growth of the impact investing marketplace and the larger capital market's interest in responsible investment are showing that impact is an important factor for business. For impact investors, financial performance is not the only thing they look at. They should also require companies to measure and manage their impact on a broader stakeholder group. Impact measurement and management enables investors to understand how their investments are affecting their target groups and general well-being of the businesses.

Legal innovation is also necessary to align the interests of business with the interests of society and to allow companies and investors to pursue a higher purpose than just profit maximisation, especially as they scale via the capital markets. Regulation that is weak or non-existent will make it easy for exploitation of communities and environment to maximise their profits. To enable regulation, measurement has to happen for lawmakers to analyse outcome and impact created through business intervention.

The B Movement, as well as other high-impact business movements like Fair Trade, Organic Certification and SDGs, is offering standards that can enable businesses to track their impact on people and planet. When all businesses start embedding practices that are sustainable and inclusive for all in the market, this will be the right step in ensuring shared and durable prosperity for all.

\section{Acknowledgements Competing interests}

The author declares that she has no financial or personal relationships that may have inappropriately influenced her in writing this article.

\section{Disclaimer}

The views and opinions expressed in this article are those of the author and do not necessarily reflect the official policy or position of any affiliated agency of the author.

\section{References}

Barton, D., Horváth, D. \& Kipping, M., 2016, Re-imagining capitalism, Oxford University Press, Oxford.

Benefitcorp.net, 2018, Businesses, Benefit Corporation, viewed 27 February 2018, from http://benefitcorp.net/businesses

B Corp. n.d., B Corporation, viewed n.d., from https://bcorporation.net/about-b-corps B Corp. n.d., B Corporation, viewed n.d., from https://bcorporation.net/certification

BIA registration, n.d., B Imapct Assessment, viewed n.d., from bimpactassessment. net.

B-labeastafrica.net, 2018, B Lab East Africa, Peperuka Catch Up, viewed 25 February 2018, from https://b-labeastafrica.net/case-study-peperuka//

Browne, J. \& Nutall, R., 2015, Beyond corporate social responsibility: Integrated external engagement, viewed 26 May 2018, from https://www.mckinsey. com/business-functions/strategy-and-corporate-finance/our-insights/beyondcorporate-social-responsibility-integrated-external-engagement

Brusseau, J., 2013, The business ethics workshop, vol. 1, Flat World Knowledge, Boston, MA

Faber, E., 2018, April 12, LinkedIn article, Linkedln, viewed 14 December 2018, from https://www.linkedin.com/pulse/b-corp-longer-question-emmanuel-faber-1/

Friedman, M., 1962, Capitalism and freedom, University of Chicago Press, Chicago, IL.

Giddens, M., 2018, August 3, The rise of B corps highlights the emergence of a new way of doing business, Forbes, viewed 12 January 2019, from https://www. forbes.com/sites/michelegiddens/2018/08/03/rise-of-b-corps-highlights-theemergence-of-a-new-way-of-doing-business/\#78aec83b2ed2 
Henriques, A., 2013, The triple bottom line: Does it all add up, Earthscan, London.

Kassoy, A., Houlahan, B. \& Gilbert, J.C., 2016, Impact governance and management: Fulfilling the promise of capitalism to achieve a shared and durable prosperity, Brookings Center for Effective Public Management (July), Washington, DC, pp. 1-18.

Knowles, D., 2016, April, 'Special report: 1.2 billion opportunities', The Economist, pp. 1-15.

Phillips, R.A., 2012, Stakeholder theory: Impact and prospects, Edward Elgar Publishing, Cheltenham.

Pimentel, D.A., 2018, Reward work, not wealth, Oxfam GB For Oxfam International, Oxford.
SustainAbility, 2015, 'Model behavior II strategies to rewire business', SustainAbility 1-63, viewed 27 February 2018, from http://www.sustainability.com/library/ model-behavior-ii\#.VYU7IROqqkr

United Nations Development Programme (UNDP), 2015, Impact investment in Africa: Trends, constraints and opportunities about this report, United Nations Development Programme (UNDP), New York.

Wilson, F., 2016a, Case studies, viewed January 2019, from B-Analytics: http:// b-analytics.net/customers/case-studies/using-b-impact-assessment-engageemployees

Wilson, F., 2016b, Case studies, viewed May 2018, from B-Analytics: http://b-analytics. net/customers/case-studies 


\section{Appendix 1: Impact management: Good questions drive good business.}

\section{Sample questions from the B Impact Assessment}

\section{Workers}

- Which supplementary benefits are provided to a majority of non-managerial workers? Including full-time and part-time employees. Please check all that apply.

- Free transportation or transit subsidy

- Free or subsidised meals

- Health benefits extend to immediate family (spouse and children)

- Child-care (on-site or subsidised)

- Access to local medical services or clinic (on-site or subsidised)

- Free or subsidised housing

- Other free or subsidised benefits (describe)

- None

\section{Community}

- Does your company have the following written local purchasing or hiring policies in place?

- No written local purchasing strategy in place

- Written preference at each facility to purchase from local suppliers

- Ready-to-use lists of preferred local suppliers or vendors for specific facilities

- Written preference for hiring and recruiting local managers with equitable compensation

- Preference for hiring and recruiting local staff (management and non-management) with training for employees

- Incentives for staff to live within $40 \mathrm{~km}$ of local company facility

- Other (please describe)

\section{Environment}

- Does your company monitor, record and report its energy and water usage, relative to company revenues?

- We do not currently monitor and record usage

- We monitor and record usage (no reduction targets)

- We monitor and record usage, and have specific reduction targets

- We monitor and record, set reduction targets and report progress on targets annually to a voluntary public reporting programme

- We have met or exceeded those targets in the last FY

\section{Governance}

- What is the company's highest level of corporate oversight?

- Owner or manager only

- Non-Fiduciary Advisory Board

- Board of Directors or equivalent

Source: BIA registration, n.d., B Imapct Assessment, viewed 02 March 2018, from bimpactassessment.net 


\section{Appendix 2: Example of legal commitment. \\ Legal test for Kenyan B Corps}

1. The purposes of the Company are to promote the success of the Company for the benefit of its members as a whole and, through its business and operations, to have a material positive impact on society and the environment, taken as a whole.

2. A Director shall have regard (among other matters) to:

a. the likely consequences of any decision in the long-term

b. the interests of the Company's employees

c. the need to foster the Company's business relationships with suppliers, customers and others

d. the impact of the Company's operations on the community and the environment

e. the desirability of the Company maintaining a reputation for high standards of business conduct

$f$. the need to act fairly as between members of the Company (together, the matters referred to above shall be defined for the purposes of this Article as the 'Stakeholder Interests').

3. For the purposes of a Director's duty to act in the way he or she considers, in good faith, most likely to promote the success of the Company, a Director shall not be required to regard the benefit of any particular Stakeholder Interest or group of Stakeholder Interests as more important than any other.

4. Nothing in this Article, express or implied, is intended to or shall create or grant any right or any cause of action to, by or for any person (other than the Company). 


\section{Appendix 3}

\section{The B Corp Declaration}

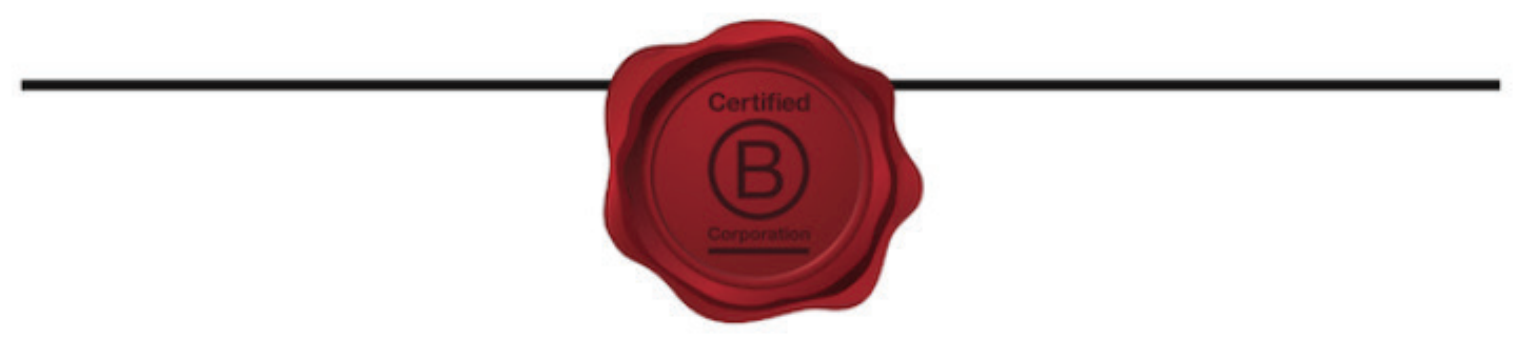

\section{DECLARATION OF INTERDEPENDENCE}

We envision a global economy that uses business as a force for good.

This economy is comprised of a new type of corporation - the B Corporation -

Which is purpose-driven and creates benefit for all stakeholders, not just shareholders.

As B Corporations and leaders of this emerging economy, we believe:

That we must be the change we seek in the world.

That all business ought to be conducted as if people and place mattered.

That, through their products, practices, and profits, businesses should aspire to do no harm and benefit all.

To do so requires that we act with the understanding that we are each dependent upon another and thus responsible for each other and future generations. 


\section{Appendix 4}

TABLE 1-A4: How the BIA compares to other impact standards.

\begin{tabular}{ll}
\hline Standard & Relationship to BIA \\
\hline Global Reporting Initiative (GRI) & Metrics used and rewarded in completing BIA. \\
$\begin{array}{l}\text { Sustainability Accounting } \\
\text { Standards Board (SASB) }\end{array}$ & $\begin{array}{l}\text { Industry metrics available as add-on to BIA; } \\
\text { utilised in B Corp eligibility review. }\end{array}$ \\
Carbon Disclosure Project (CDP) & Metrics used in completing BIA. \\
$\begin{array}{l}\text { Future Fit Business Benchmark } \\
\text { Impact Reporting Investment }\end{array}$ & $\begin{array}{l}\text { Future Fit principles incorporated into BIA. } \\
\text { IRIS metrics and definitions are incorporated in } \\
\text { Standards (IRIS) }\end{array}$ \\
$\begin{array}{l}\text { the BIA whenever possible. } \\
\text { Social Value Principles (SROI) }\end{array}$ & $\begin{array}{l}\text { The BIA has a formal partnership with Social } \\
\text { Value International and incorporates Social Value } \\
\text { principles, particularly in the Impact Business } \\
\text { Models portion of the assessment, and } \\
\text { recommends the use of SROI principles as a } \\
\text { means of outcomes measurement to supplement } \\
\text { the comprehensive practice-oriented evaluation } \\
\text { of the BIA. }\end{array}$ \\
$\begin{array}{l}\text { Fair Trade Certification, Organic } \\
\text { Incorporating their standards directly into the BIA } \\
\text { and/or utilising their systems for verification } \\
\text { purposes. }\end{array}$ \\
$\begin{array}{l}\text { Sustainable Development Goals } \\
\text { (SDGs) }\end{array}$ & $\begin{array}{l}\text { B Lab has partnered with UNGC to develop an } \\
\text { SDG platform with the BIA as a basis. This will } \\
\text { enable for businesses taking the BIA to contribute } \\
\text { in a measured way to the UN SDG agenda. }\end{array}$ \\
\hline
\end{tabular}

Note: Based on internal work at B Lab.

BIA, B impact assessment. 